\title{
ФИНАНСОВЫЕ РЫНКИ В ПЕРИОД ПАНДЕМИИ: ТЕНДЕНЦИИ, ПРОГНОЗЫ, ТОЧКИ РОСТА
}

\section{FINANCIAL MARKETS: PANDEMIC STATUS AND GROWTH POINTS}

\section{S. Zubkova \\ V. Mashkina}

Summary. This article examines trends that manifested in the financial market during the pandemic period. The financial shocks that all countries faced had a significant impact on the financial sector. The article identifies the leaders of stock markets, including representatives of the medical sector, IT, telecommunications and some others. Also, some forecasts for the development of the world and domestic financial market are given.

Keywords: financial market, pandemic, currency depreciation, securities, stock market.

\author{
Зубкова Светлана Валерьевна \\ К.э.н., доцент, Финансовый университет при \\ Правительстве РФ \\ zubkovasv@inbox.ru \\ Машкина Валерия Андреевна \\ Финансовый университет при Правительстве РФ \\ lerka-neka@yandex.ru
}

Аннотация. В данной статье рассмотрены тенденции, которые проявились на финансовом рынке в период пандемии. Финансовые шоки, с которыми столкнулись все страны оказали существенное влияние и на сферу финансов. В статье определены лидеры фондовых рынков, в числе которых оказались представители медицинской сферы, IT, телекоммуникаций и некоторые другие. Также, приводятся некоторые прогнозы по развитию мирового и отечественного финансового рынка.

Ключевые слова: финансовый рынок, пандемия, падение курса валют, ценные бумаги, фондовый рынок.

на развивающихся рынках, где произошел масштабный отток капитала.

Также, важно то, что валюты развивающихся стран существенно снизились по отношению к доллару США, так как местные фондовые рынки начали ориентироваться именно на валюты развитых стран. Российский рубль тоже оказался под давлением. Это связано и с пандемией, и с падением цены на нефть, и с геополитическими факторами. Когда коронавирус стал уже очевидной катастрофой для всех, инвесторы начали отказываться от рискованных активов, в том числе и рубля, и вкладывать в защитные активы (например, золото). Наибольшее ослабление российской валюты было отмечено в марте $(80,88$ курс доллара США, 86,7 - евро на 24.03) и ноябре (80,57 - доллар США, 93,75 - курс евро на 03.11) - эти периоды как раз совпадают с началом первой и второй волны COVID-19. Прогнозы экспертов сводятся к тому, что создание вакцины от коронавируса и начало массовой вакцинации в разных странах приведет к стабилизации и укреплению национальной валюты. Однако, очевидно, что все зависит также и от геополитической обстановки, новых санкций и др.

Интересно то, что уже к маю ведущие экономики, а соответственно и фондовые рынки практически полностью восстановились. Это связано прежде всего 


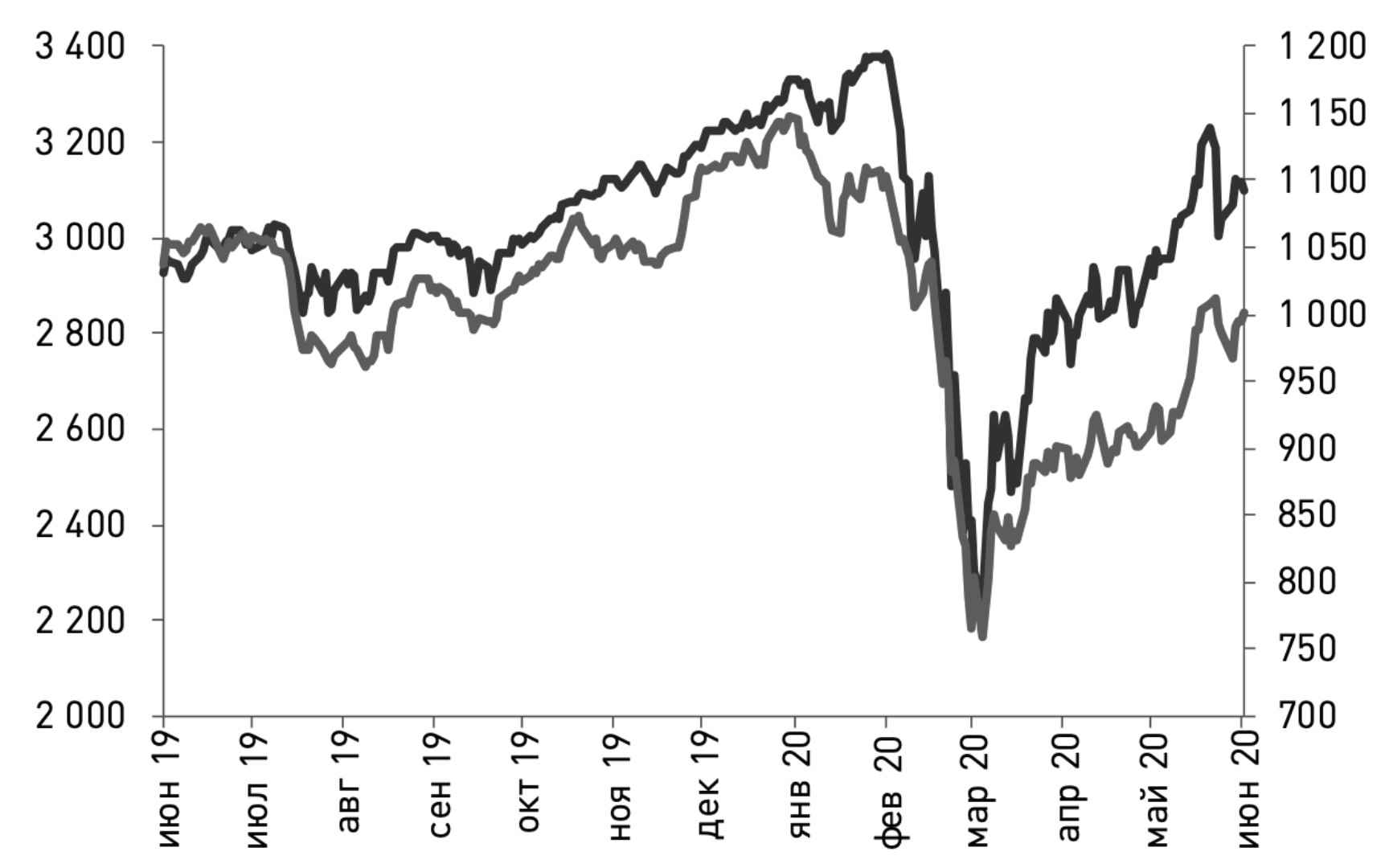

\section{$\longrightarrow$ S\&P $500 \longrightarrow$ MSCI EM}

Рис. 1. Динамика фондового рынка США (S\&P 500) и фондовых рынков развивающихся стран (MSCI EM), 2019-2020 гг.[1]

с мерами правительств по стимулированию экономики: снижение процентных ставок, льготы для бизнеса и т.д. Снижение процентных ставок Центральными банками привело к падению ставок на депозиты. Интерес к фондовым рынкам существенно увеличился: население обратилось на рынок для получения большего дохода, чем в коммерческих банках. Антон Новиков, аналитик «Фридом Финанс»: «Пандемия с точки зрения притока новых участников на биржи сказалась довольно положительно. На всех значимых площадках наблюдался рост торгов. Скорее всего данная тенденция продолжится, так как доходности банковских депозитов по всему миру крайне низкие и часто не опережают инфляцию.» [2]. Однако это послужит не только преимуществом для развития рынка, но и породит проблемы, связанные с тем, что часть «новоиспеченных» инвесторов не обладает абсолютно никакими знаниями по работе на фондовом рынке, что говорит о спонтанности и непредсказуемости их действий.
Банки скорее всего будут удерживать своих клиентов, чтобы сохранить какой-то баланс, чтобы депозитный рынок оставался стабильным. Банк России, сохранив в очередной раз 12 февраля 2021 года ключевую ставку на уровне 4,25\%, по сути, не дал каких-то возможностей для коммерческих банков для повышения ставки по депозитам. Однако, Эльвира Набиуллина заявила о том, что Банк России будет переходить к нейтральной денежно-кредитной политике, и дальнейшие события подтвердили ее слова, в настоящее время ставка уже 5,5\%, и есть мнение, что ставка будет дальше повышаться.

В любом случае коммерческие банки в посткоронавирусный период либо поднимают ставки, чтобы удержать своих клиентов, либо предлагают им более широкий спектр услуг в пакете. Сохранение клиентской базы и поддержание дополнительной ликвидности необходимы банкам, чтобы увеличить объемы кредитования, что важно в период кризисов. 


\section{Диаграмма изменения максимальной процентной ставки за выбранный период}

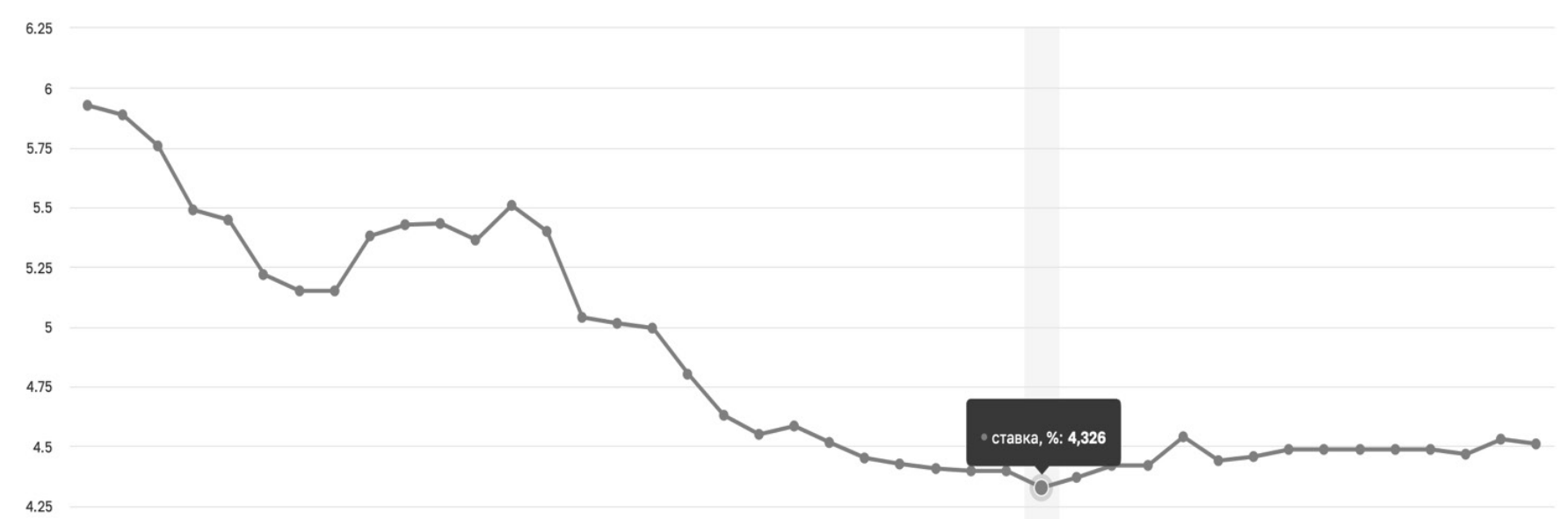

Рис. 2. Диаграмма изменения максимальной процентной ставки топ-10 коммерческих банков РФ в период 1 декады января 2020 по 3 декаду февраля 2021 года [4]

Также, угроза для банков - не только фондовый рынок, который может показаться для населения наиболее привлекательным, но и цифровой рубль. Банки будут конкурировать теперь с «третьей формой денег», которая будет эмитироваться Банком России. Вынужденное поднятие ставок будет также связано и с тем, что вклады, открытые в конце 2019 года или начале 2020 будут истекать: это значит, что клиенты могут отказаться от низкодоходных депозитов в пользу тех же ценных бумаг или даже наличности [3].

Таким образом, коронавирус обозначил новые реалии для банковского сектора России: коммерческие банки будут предпринимать попытки сохранить средства клиентов путем поднятия ставок и создания комплексных продуктов, которые могут заинтересовать потребителя. На рисунке 2 мы видим, что уже с начала октября наблюдается тенденция к увеличению максимальной процентной ставки. Банки уже сейчас предлагают новые условия для клиентов - сезонные вклады, промовклады. Иначе, деньги могут перетечь на фондовый рынок, что поставит под вопрос стабильность банковской сферы и финансового рынка в целом.

Следующая тенденция состоит в том, что в пандемийный период существенно изменились предпочтения инвесторов - внимание было обращено на те компании, которые выиграли из-за коронавируса, например фармацевтических сектор, телекоммуникации и IT. По мнению экспертов спрос на данные сферы будет расти и в будущем, однако, многие компании уже переоценены. Примером колоссального роста можно назвать акции Zoom - только за второй квартал выручка компании выросла на 355\% (до \$633,5 млн); ак- ции за год выросли 490\%[5]. Из фарма-сферы лидером роста стали акции компании Moderna - биотехнологическая компании в числе многих занималась разработкой вакцины от коронавируса и довольно успешно проводила клинические испытания. Эти факторы подогревали оптимизм инвесторов: цена акций за год выросла на $301 \%$ [6]. На фоне грандиозных успехов одних компаний наблюдались и грандиозные снижения у других. Основной удар пришелся на добывающие отрасли (Chesapeake Energy), так существенно сократился спрос на нефте; сферу перевозок и туризма из-за мировых карантинных мер и локдаунов (Carnival, Boeing, American Airlines) и др.

Что касается каких-либо прогнозов, многие эксперты уверены, что рынки будут расти, это касается и российского фондового рынка. Президент НАУФОР отмечает: «Соответственно, будет развиваться и индустрия - рост численности клиентов требует технологических решений, повышения разнообразия с одной стороны и стандартизации услуг с другой стороны, рост активов будет позволять ей все больше зарабатывать на них, а не на комиссиях, будет расти роль консультационной поддержки и управления портфелями.[7].

Финансовый рынок изменяется, приходят новые участники, которые могут конкурировать в современных реалиях, адаптироваться к новым процессам и тенденциям. Будущее финансового рынка в «посткоронавирусный» период зависит от того, когда пандемия закончится, от результатов вакцинации; от действий правительств в области снятия ограничений, новых механизмов для трансграничного перемещения граждан, а также в сфере стимулирования экономики. Уже точ- 
но можно сказать, что далеко не все компании смогут восстановиться после кризисного года, тем более что и предпочтения инвесторов могут измениться и в долгосрочной перспективе.

Пандемия COVID-19 существенным образом повлияла на мировые финансовые рынки: в начале года это был финансовый шок, но уже к маю 2020 г. отдельные сектора восстановились; кто-то показал существенный рост, а кто-то обанкротился. Количество инвесторов увеличивается, а их предпочтения меняются. Никто не может дать однозначных прогнозов, однако ясно то, что финансовый рынок и мировая экономика постепенно приспособились к функционированию в новых условиях.

\section{ЛИТЕРАТУРА}

1. Аналитический бюллетень НИУ ВШЭ об экономических и социальных последствиях коронавируса в России и в мире.— 2020.- № 7. [Электронный ресурc]. URL: https://www.hse.ru/data/2020/06/25/1607268459/HSE_Covid_07_2020_1_6.pdf (дата обращения: 05.02.2021).

2. Гид для инвестора: стратегии и тренды в эпоху ковида // Forbes. [Электронный ресурc]. URL: https://www.forbes.ru/brandvoice-photogallery/ tinkoff/407069-gid-dlya-investora-trendy-i-strategii-v-epohu-kovida?photo=1 (дата обращения: 16.02.2021).

3. На финансовые рынки пандемия оказала положительное влияние // Финам. [Электронный ресурc]. URL: https://www.finam.ru/analysis/marketnews/ na-finansovye-rynki-pandemiya-okazala-polozhitelnoe-vliyanie-20200907-17100/ (дата обращения: 07.02.2021).

4. Банкам придется повысить ставки по депозитам //Ведомости. [Электронный ресурc]. URL: https://www.vedomosti.ru/economics/ articles/2021/02/14/857895-bankam-depozitam (дата обращения: 01.03.2021).

5. Официальный сайт ЦБ РФ. [Электронный ресурc]. URL: https://cbr.ru/statistics/avgprocstav/? UniDbQuery.Posted=True\&UniDbQuery. From=1.01.2020\&UniDbQuery.To=3.02.2021 (дата обращения: 03.03.2021).

6. Гаврикова В. Финансовые рынки в эпоху COVID: новые звезды и потерянные деньги // РБК. [Электронный pecypc]. URL: https://quote.rbc.ru/ card/5fad079f9a7947f70fd42880 (дата обращения: 05.02.2021).

7. Президент НАУФОР: мы не увидели никакого вреда, который нанесла индустрии пандемия // Интерфакс. [Электронный ресурс]. URL: https://www. interfax.ru/interview/725183 (дата обращения: 07.02.2021).

(c) Зубкова Светлана Валерьевна ( zubkovasv@inbox.ru ), Машкина Валерия Андреевна ( lerka-neka@yandex.ru ).

Журнал «Современная наука: актуальные проблемы теории и практики»

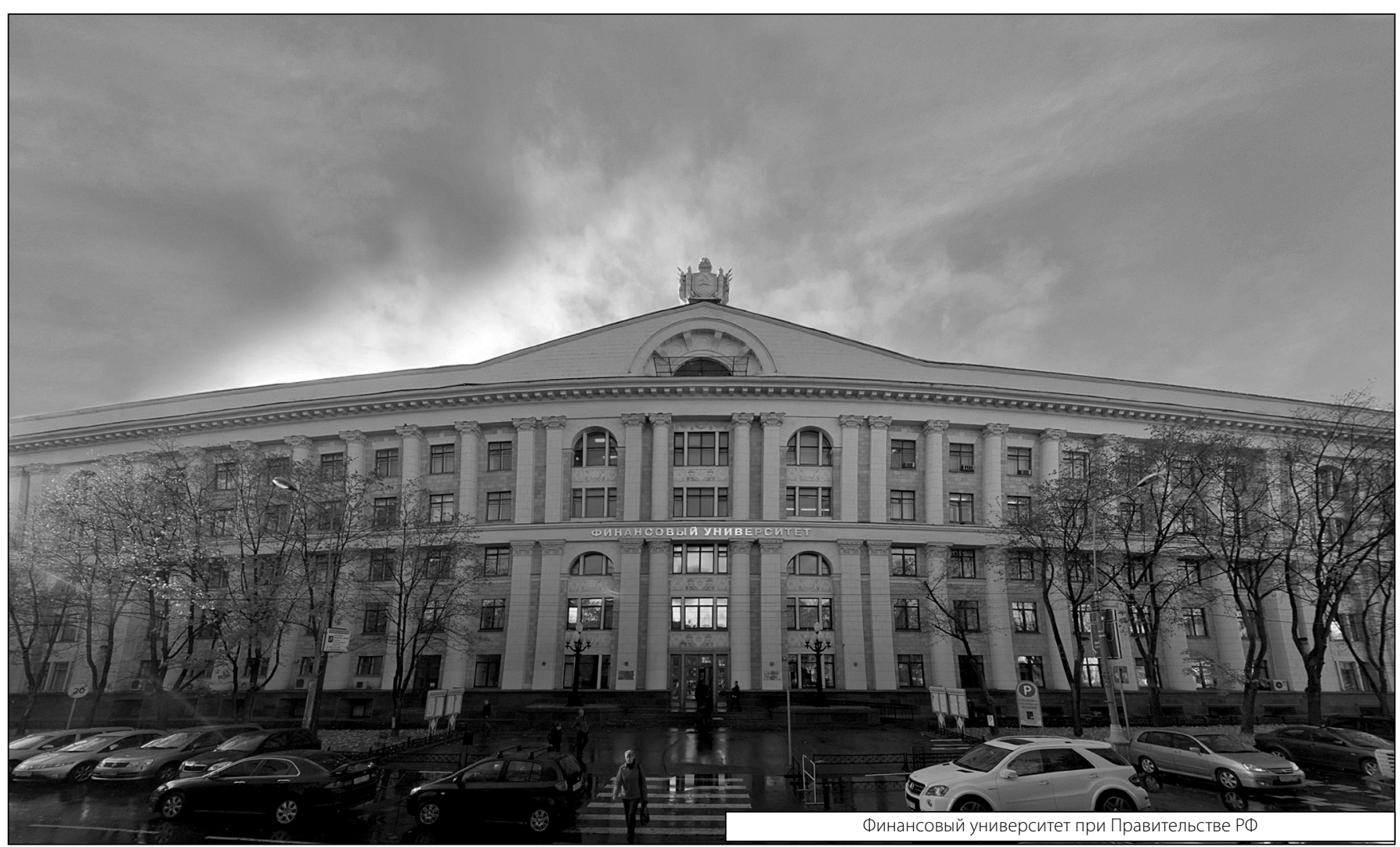

